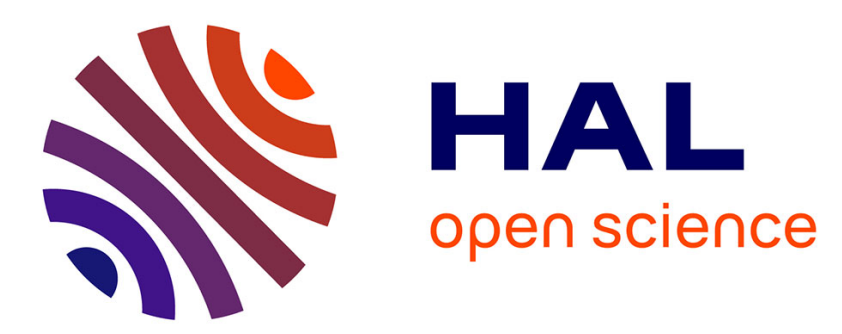

\title{
New synthetic route to 2,2,6,6-tetraethylpiperidin-4-one: A key-intermediate towards tetraethyl nitroxides
}

\author{
Nikola Babić, Fabienne Peyrot
}

\section{To cite this version:}

Nikola Babić, Fabienne Peyrot. New synthetic route to 2,2,6,6-tetraethylpiperidin-4-one: A key-intermediate towards tetraethyl nitroxides. Tetrahedron Letters, 2019, 60 (44), pp.151207. 10.1016/j.tetlet.2019.151207 . hal-02491069

\section{HAL Id: hal-02491069 \\ https://hal.science/hal-02491069}

Submitted on 20 May 2020

HAL is a multi-disciplinary open access archive for the deposit and dissemination of scientific research documents, whether they are published or not. The documents may come from teaching and research institutions in France or abroad, or from public or private research centers.
L'archive ouverte pluridisciplinaire HAL, est destinée au dépôt et à la diffusion de documents scientifiques de niveau recherche, publiés ou non, émanant des établissements d'enseignement et de recherche français ou étrangers, des laboratoires publics ou privés. 


\section{New synthetic route to 2,2,6,6-tetraethylpiperidin-4-one: a key-intermediate towards tetraethyl nitroxides}

Nikola Babića and Fabienne Peyrot ${ }^{a, b,{ }^{*}}$

\section{Affiliations:}

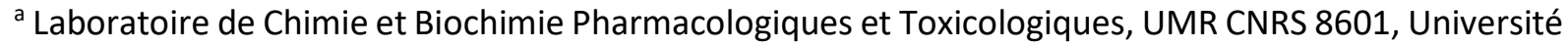
Paris Descartes, Sorbonne Paris Cité, 45 rue des Saints-Pères, 75006 Paris, France

${ }^{\mathrm{b}}$ Institut National Supérieur du Professorat et de l'Éducation (INSPE) de l'Académie de Paris, Sorbonne Université, 10 rue Molitor, 75016 Paris, France

* Corresponding author: Tel.: +33 (0)1 428621 75, fax: +33 (0)1 428643 84, e-mail: fabienne.peyrot@parisdescartes.fr

\section{Abstract}

A new synthetic route to 2,2,6,6-tetraethylpiperidin-4-one and derived aminoxyl (nitroxide) radicals is described. In this preliminary work, 2,2,6,6-tetraethylpiperidin-4-one was obtained from ethyl acetoacetate in $3 \%$ yield over eight steps, relying only on common reagents and laboratory equipment for organic synthesis.

Keywords: Aminoxyl radical; Spin probe; Synthesis; EPR.

\section{Graphical Abstract}

New route to tetraethyl aminoxyl (nitroxide) radicals

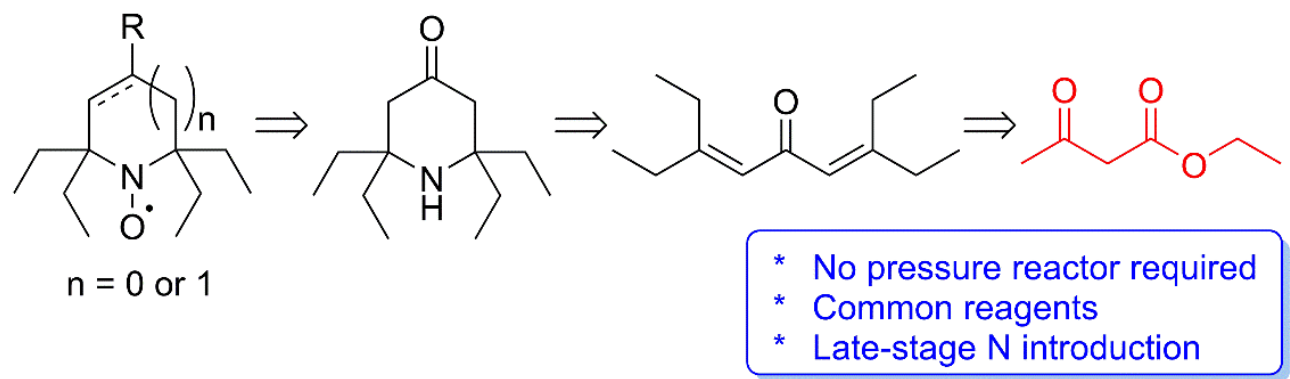




\section{Introduction}

Nitroxides are a class of organic compounds containing a $\mathrm{N}-\mathrm{O}^{\bullet}$ functional group. Unusually for organic molecules, many nitroxides are stable radicals. Due to their stability but interesting reactivity, they have found a myriad of applications including: spin labelling, ${ }^{1}$ radical-mediated polymerization, ${ }^{2}$ oxoammonium-catalyzed oxidation of alcohols, ${ }^{3}$ and redox probes in biology, ${ }^{4,5}$ to name but a few.

While significant research has been done on tetramethyl-substituted nitroxides since the 1970 s to understand the chemistry and behavior of nitroxides in a biological context, ${ }^{6-13}$ the recent development of a generation of nitroxides that are stable against reduction has opened new perspectives for in vivo applications. ${ }^{14,15}$ The introduction of four ethyl groups in place of methyls dramatically increases the resistance of the $\mathrm{N}-\mathrm{O}^{*}$ functional group against reduction to hydroxylamine $(\mathrm{N}-\mathrm{OH})$ by bioreductants, due to both a steric effect and a decreased redox potential of the aforementioned pair. ${ }^{16,17}$ The insertion of ionizable carboxylate groups in the structure affords additional protection through electrostatic repulsion as recently shown with pyrrolidine nitroxides. ${ }^{18}$

Nitroxides derived from 2,2,6,6-tetraethylpiperidin-4-one 1, such as compound 2, have been used in vivo, ${ }^{19-22}$ and are also a cornerstone in the synthesis of other tetraethyl nitroxides such as pyrrolidine- and pyrroline-based ones (Scheme 1). ${ }^{15,23-26}$ However, the presence of bulky ethyl groups in tetraethyl-substituted nitroxides makes them far more difficult to synthesize than their methylsubstituted counterparts. In EPR spectroscopy and imaging applications, ${ }^{15} \mathrm{~N}$-labelling of the nitroxide affords higher sensitivity thanks to the reduced spectral multiplicity $\left(2 I+1\right.$ lines, with nuclear spins $I\left({ }^{15} \mathrm{~N}\right)$ $=1 / 2$ vs. $\left.\left({ }^{14} \mathrm{~N}\right)=1\right)$; however ${ }^{15} \mathrm{~N}$-sources are very expensive, making efficient synthetic routes with late introduction of the nitrogen atom even more crucial. Several pathways for the synthesis of tetraethyl nitroxides already exist, but they are not without drawbacks. The methods developed by the Utsumi group and based on intermediates 7 and $\mathbf{8}$ (Fig. 1) suffer from low and unreliable yields while the introduction of the nitrogen atom occurs in the first steps of the synthesis, making the target compound very expensive. ${ }^{14,19,27}$ Alternative strategies through symmetric dienone $\mathbf{9}$, initially proposed by the Studer group, ${ }^{28}$ allow introduction of the nitrogen at a late stage of the synthesis (Fig. 1). However, these authors later dismissed their own pathway on the grounds of low yields, before going back to synthetic routes involving intermediate $7 .{ }^{29}$ More recently, the Arimoto group successfully prepared several grams of ${ }^{15} \mathrm{~N}$-labelled nitroxide $\mathbf{2}$ via dienone intermediate 9 , ${ }^{22}$ but their procedure requires specific equipment to perform a Meyer-Schuster rearrangement under elevated $\mathrm{CO}_{2}$ pressure. This key step is highly sensitive to the reaction conditions ${ }^{30}$ and difficult to reproduce.

Herein, we propose a new synthetic route for obtaining piperidine-based nitroxides through dienone derivative 9, relying only on common reagents and laboratory equipment for organic synthesis. A set of tetraethyl-substituted piperidine nitroxides with potentially different abilities to cross cell membranes was prepared in view of biological applications and their resistance against reduction by ascorbate was assessed.

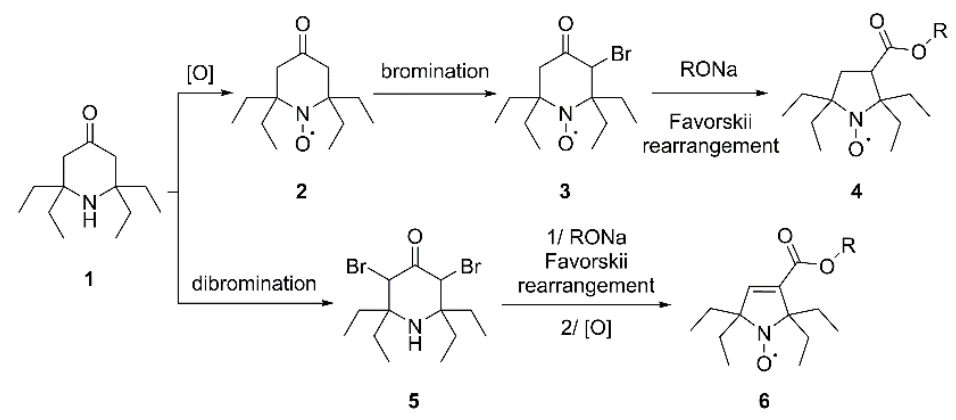

Scheme 1. 2,2,6,6-Tetraethylpiperidin-4-one 1 as a key intermediate in the synthesis of tetraethylsubstituted nitroxides based on piperidine 2, pyrrolidine 4, and pyrroline 6 according to the literature. ${ }^{15,23-26}[\mathrm{O}]=$ oxidation, $\mathrm{R}=\mathrm{H}$ or alkyl group. 

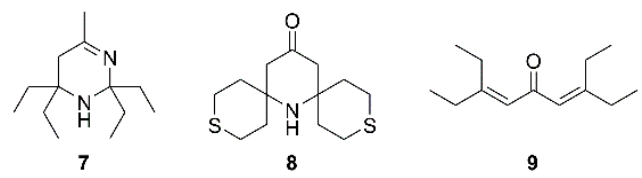

Figure 1. Key intermediates in the synthesis of tetraethyl nitroxides.

\section{Results and Discussion}

Our initial plan was to create the carbon backbone of dienone 9 and to introduce four ethyl groups in one step by submitting dioxolane-protected diethyl 3-oxoglutarate to a Grignard reaction with ethylmagnesium bromide. Despite several attempts, this strategy was unsuccessful, presumably due to steric reasons, even though similar examples exist in the literature. ${ }^{31}$ We therefore had to proceed via a stepwise route.

Our synthetic route towards 2,2,6,6-tetraethylpiperidin-4-one 1 is presented in Scheme 2. First, the 1,3-dianion of ethyl acetoacetate was generated by deprotonation with two equivalents of freshly prepared lithium diisopropylamide at $-50{ }^{\circ} \mathrm{C}$ in tetrahydrofuran. When one equivalent of 3pentanone was added, regioselective addition of the terminal carbon of the dianion to the ketone provided $\delta$-hydroxy- $\beta$-keto ester $\mathbf{1 1}$ in $68 \%$ yield, comparable to similar examples in the literature. ${ }^{32}$ Compound $\mathbf{1 2}$ was then obtained by reducing $\mathbf{1 1}$ with sodium borohydride $\left(\mathrm{NaBH}_{4}\right) \cdot \mathrm{NaBH}_{4}$ is used commonly for converting ketones and aldehydes to alcohols, whereas esters are usually stable under the typical reaction conditions. However, when neighboring functional groups such as oxo, hydroxyl, or carboxylic acids are present, sodium borohydride can reduce esters to alcohols. ${ }^{33}$ Indeed, when we attempted the reduction of the keto group of compound $\mathbf{1 1}$ using typical conditions with several equivalents of sodium borohydride in methanol at room temperature, a significant amount of ester was also reduced to give the corresponding triol. It is likely that $\mathrm{NaBH}_{4}$ partially reacts with methanol and the hydroxyl groups in compound $\mathbf{1 1}$ to form a trialkylborate ${ }^{32}$ that acts as a Lewis acid, activates the ester group, and facilitates its reduction, as illustrated by structures 11a and 12a in Figure 2.

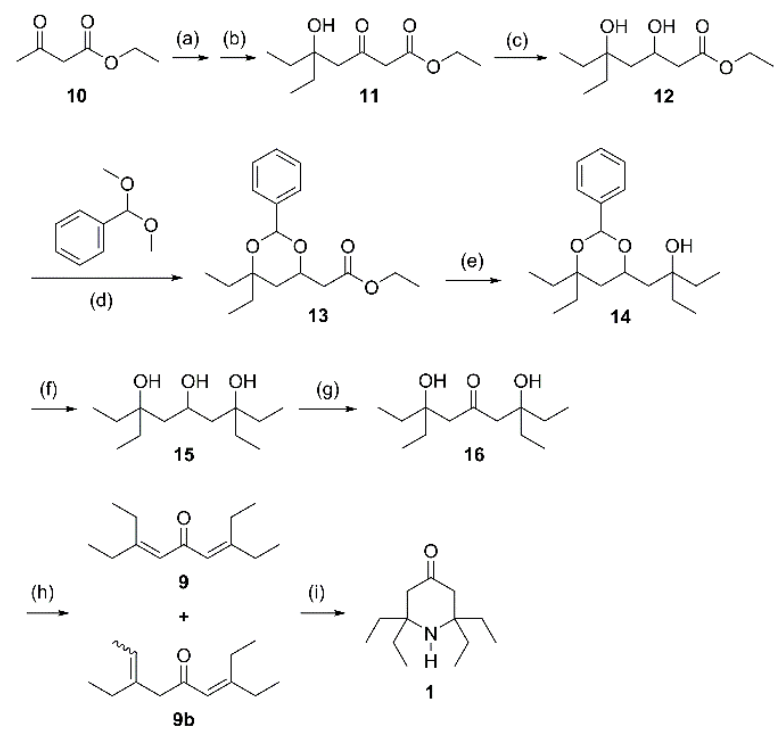

Scheme 2. Synthesis of 2,2,6,6-tetraethylpiperidin-4-one. Reagents and conditions: (a) LDA (2 eq.), $\mathrm{THF},-50{ }^{\circ} \mathrm{C}, 1 \mathrm{~h}$; (b) 3-pentanone (1 eq.), THF, - $50{ }^{\circ} \mathrm{C}, 3 \mathrm{~h}, 68 \%$ over two steps; (c) $\mathrm{NaBH}_{4}$ (2.5 eq.), $\mathrm{MeOH} / \mathrm{THF}(1: 3), 0{ }^{\circ} \mathrm{C}$; (d) benzaldehyde dimethyl acetal (10 eq.), PTSA (cat.), $\mathrm{CH}_{2} \mathrm{Cl}_{2}, 22^{\circ} \mathrm{C}$, overnight, $43 \%$ over two steps; (e) EtMgBr (8 eq.), THF, 83\%; (f) $3 \mathrm{M} \mathrm{HCl}$, EtOH, $22{ }^{\circ} \mathrm{C}, 16 \mathrm{~h}$; (g) Jones reagent (2 eq.), acetone, $48 \%$ over two steps; (h) conc. $\mathrm{H}_{2} \mathrm{SO}_{4}, \mathrm{CHCl}_{3}, 1.5 \mathrm{~h}$; (i) $\mathrm{NH}_{3}, \mathrm{EtOH}, 50{ }^{\circ} \mathrm{C}, 3$ days, $29 \%$ over two steps. cat. $=$ catalytic, conc. $=$ concentrated, $\mathrm{LDA}=$ lithium diisopropylamide, PTSA, $p$ toluenesulfonic acid, THF = tetrahydrofuran. 

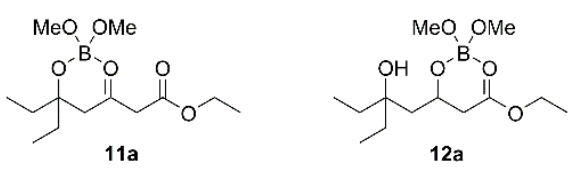

Figure 2. Reduction of compound $\mathbf{1 1}$ and eventually $\mathbf{1 2}$ by $\mathrm{NaBH}_{4}$ could be facilitated by the formation of borate complexes 11a and 12a.

It has been reported ${ }^{32}$ that performing the reduction in tetrahydrofuran at a low concentration of $\mathrm{NaBH}_{4}(0.2 \mathrm{M})$ prevents reduction of the ester functional group. In our hands, however, although the ester group was not reduced, the reaction was not complete even after several days. It seems that the reduction of the keto group is also accelerated by formation of complex 11a (Fig. 2) and is thus very slow in its absence. Finally, a compromise was found by performing the reaction in a mixture of tetrahydrofuran and methanol at $0{ }^{\circ} \mathrm{C}$ with $0.5 \mathrm{M} \mathrm{NaBH}_{4}$. The conversion was complete after a few hours with little side product formation. The crude product was thus used in the next step without purification.

Direct Grignard reaction on diol $\mathbf{1 2}$ was prevented, presumably due to a negative charge close to the reactive ester functional group. Our next move was thus to prepare the isopropylidene ketal of diol 12. The typical procedure involves dissolving the substrate, in this case diol 12, in 2,2dimethoxypropane and stirring with a catalytic amount of $p$-toluenesulfonic acid. Unfortunately, after several trials, only a low yield $(<20 \%)$ of ketal $\mathbf{1 7}$ was isolated (Fig. 3 ). Various attempts at changing the solvent or the reagent (to either 2-methoxypropene or acetone in the presence of dehydrating agents such as aluminum chloride, trimethylsilyl chloride, or molecular sieves) failed to increase the yield. Therefore, benzylidene acetal protection was tested instead. Diol $\mathbf{1 2}$ was reacted with ten equivalents of benzaldehyde dimethyl acetal in dry dichloromethane and a catalytic amount of $p$ toluenesulfonic acid. After stirring at $22{ }^{\circ} \mathrm{C}$ for twenty-four hours, acetal $\mathbf{1 3}$ was isolated by column chromatography in an approximately $70 \%$ yield (calculated from the ${ }^{1} \mathrm{H}$ NMR spectra).

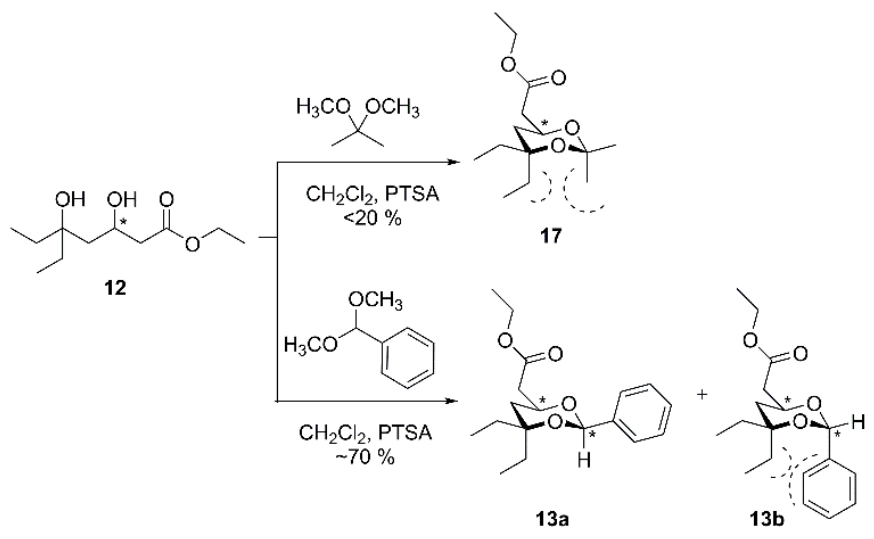

Figure 3. Influence of steric hindrance on the protection of diol $\mathbf{1 2 .}$

Steric effects can explain the unsuccessful acetonide protection shown in Figure 3. In the case of six-membered cyclic ketal 17, 1,3-diaxial interactions destabilize the structure, while such steric strain is absent in the preferred conformation of the major diastereomer 13a. Determining the exact ratio of $13 a$ and $\mathbf{1 3 b}$ in the product by ${ }^{1} \mathrm{H}$ NMR was not straightforward due to overlapping signals.

Transformation of ester $\mathbf{1 3}$ to tertiary alcohol $\mathbf{1 4}$ proceeded smoothly under the typical conditions for the addition of two equivalents of Grignard reagent to an ester. Ester $\mathbf{1 3}$ was added to a solution of ethylmagnesium bromide in tetrahydrofuran at $0{ }^{\circ} \mathrm{C}$. After stirring at $22^{\circ} \mathrm{C}$ for three hours, the conversion was complete, to afford tertiary alcohol 14 in $83 \%$ yield. The carbon skeleton of the target compound was now installed. As compound $\mathbf{1 4}$ was poorly soluble in water, a mixture of ethanol and $3 \mathrm{M}$ aqueous hydrochloric acid was used for acid catalyzed hydrolysis of the benzylidene protecting 
group. After several hours, the conversion was completed to give triol $\mathbf{1 5}$ that was used in the next step without purification.

Next, we tried to oxidize the secondary hydroxyl group in triol $\mathbf{1 5}$ using a mild oxidizing agent, Dess-Martin periodinane in dichloromethane. To our surprise, no reaction was observed, even after increasing the amount of periodinane and the reaction time. Oxidation of alcohols by Dess-Martin periodinane occurs through the initial substitution of one acetate by the hydroxyl group of the alcohol to be oxidized. The carbon atom bearing the hydroxyl group loses a proton and the electron pair forms a carbonyl $\pi$-bond; at the same time, the electron pair of the coordination bond is accepted by iodine with simultaneous loss of another acetate. In the case of triol $\mathbf{1 5}$, it is possible that all three acetates are substituted by hydroxyl groups of the triol forming stable complex 15a and essentially prevents oxidation (Fig. 4).

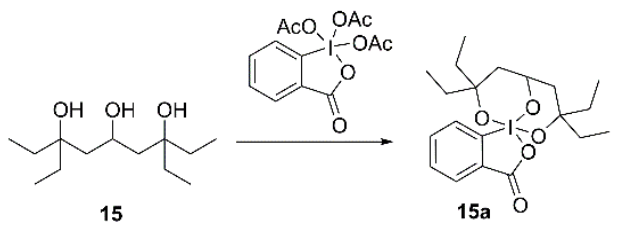

Figure 4. Possible formation of stable complex 15a preventing the oxidation of 15 by Dess-Martin periodinane.

The secondary hydroxyl group of triol $\mathbf{1 5}$ was successfully oxidized using Jones reagent. Two equivalents of chromium trioxide were added at $0{ }^{\circ} \mathrm{C}$ and stirred for two hours to achieve full conversion. The desired $\beta$-dihydroxy ketone 16 was purified by column chromatography, and isolated in $48 \%$ yield over two steps. Double dehydration was achieved by heating $\beta$-dihydroxy ketone 16 at reflux in chloroform with a catalytic amount of concentrated sulfuric acid. A mixture of dienone $\mathbf{9}$ and isomerized $\beta, \gamma$-unsaturated ketones $\mathbf{9 b}$ was obtained and used in the next step without purification. The ring closure by double Michael addition was performed following the protocol by Wetter and coworkers. ${ }^{28}$ Piperidinone 1 was purified by column chromatography and isolated in $29 \%$ yield over two steps, comparable to yields reported in the literature. ${ }^{28}$

With the intention to prepare a set of nitroxides for biological applications with potentially different abilities to cross cell membranes, we decided to prepare the 4-carboxy-analogue $\mathbf{2 0}$ and the corresponding acetoxymethoxy derivative $\mathbf{2 1}$ (Scheme 3). Compound $\mathbf{2 0}$ is expected to be negatively charged at physiological $\mathrm{pH}$ and unable to cross cell membranes, while incorporation of an esterasesensitive acetoxymethoxy group is a well-established strategy to achieve intracellular accumulation of nitroxides. ${ }^{34,35}$ Nitroxides $\mathbf{2}$ and $\mathbf{1 8}$ have been described as blood-brain-barrier permeant, ${ }^{19,22}$ and were prepared as references.

Nitroxide $\mathbf{2}$ was obtained in 75\% yield from piperidinone 1 following the procedure by Kinoshita and co-workers ${ }^{14}$ with slight modifications (Scheme 3). Treatment of compound $\mathbf{2}$ with sodium borohydride afforded nitroxide 18 in $91 \%$ yield (Scheme 3 ). Following a procedure described for tetramethyl analogues, ${ }^{36}$ the keto group of compound $\mathbf{2}$ was converted to nitrile $\mathbf{1 9}$ using the Van Leusen reaction. Then, nitroxide $\mathbf{2 0}$ was obtained by base-catalyzed hydrolysis of the nitrile function in 19 ( $56 \%$ yield over two steps after purification by column chromatography on silica). The acetoxymethoxy derivative of compound $\mathbf{2 0}$ was prepared according to literature procedures $\mathrm{s}^{35}$ by nucleophilic substitution on bromomethyl acetate with the carboxylate anion of compound 20 (Scheme 3). Compound $\mathbf{2 1}$ was isolated in $60 \%$ yield after purification. 


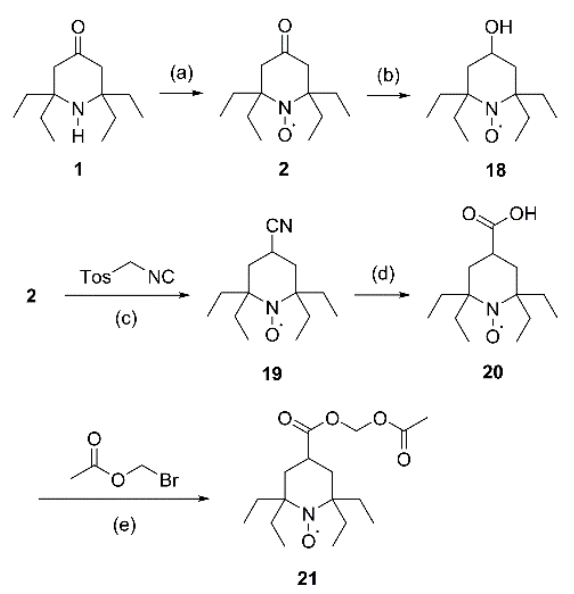

Scheme 3. Synthesis of tetraethyl-substituted piperidine nitroxides $\mathbf{2}, \mathbf{1 8}, \mathbf{2 0}$, and $\mathbf{2 1}$ from piperidone 1. Reagents and conditions: (a) $\mathrm{Na}_{2} \mathrm{WO}_{4}, 50 \% \mathrm{H}_{2} \mathrm{O}_{2}, \mathrm{EtOH}, 75 \%$; (b) $\mathrm{NaBH}_{4}, \mathrm{MeOH}, 22^{\circ} \mathrm{C}, 24 \mathrm{~h}, 91 \%$; (c) tosylmethyl isocyanide, $\mathrm{KOtBu}$, tBuOH/DME; (d) $\mathrm{Ba}(\mathrm{OH})_{2}, \mathrm{NaOH}, \mathrm{H}_{2} \mathrm{O}$, reflux, $24 \mathrm{~h}, 56 \%$ over two steps; (e) bromomethyl acetate, $\mathrm{K}_{2} \mathrm{CO}_{3}, \mathrm{DMSO}, 22^{\circ} \mathrm{C}, 2 \mathrm{~h}, 60 \%$. DME = dimethoxyethane, Tos = tosyl.

We then examined the stability of the synthesized nitroxides against reduction with sodium ascorbate using a previously described stopped-flow/EPR setup. ${ }^{37}$ This reaction is extensively used for evaluation of the stability of newly synthesized nitroxides for in vivo applications because the stability against reduction by ascorbate correlates well with their in vivo stability. ${ }^{38}$ Table 1 lists the initial second-order rate constants $\left(k_{0}\right)$ for the reaction between ascorbate and the nitroxide radicals. Measured reduction rates for nitroxides $\mathbf{2}$ and $\mathbf{1 8}$ were compatible with results from the literature, ${ }^{39}$ while nitroxide $\mathbf{2 0}$ demonstrated increased stability. A similar behavior has previously been reported for tetramethyl nitroxides and tetraethyl pyrrolidine nitroxides and was attributed to electrostatic repulsion between the carboxylate and the ascorbate monoanion at physiological $\mathrm{pH}^{7,9,18}$ These results suggest that it should be feasible to load cells with high concentrations of compound $\mathbf{2 0}$ via incubation with its esterase-hydrolysable derivative $\mathbf{2 1}$. Biological assays of the present nitroxides are currently underway.

Table 1. Second-order rate constants $\left(k_{0}\right)$ for the reaction of various nitroxide radicals with sodium ascorbate extracted from initial reaction rates ${ }^{\mathrm{a}}$ or from the literature.

\begin{tabular}{|c|c|c|}
\hline Nitroxide & $\mathbf{k}_{0}\left(\mathbf{s}^{-1} \mathbf{M}^{-1}\right)$ & Source \\
\hline $\mathbf{2}$ & $0.047 \pm 0.009$ & This work \\
& $0.066 \pm 0.001$ & Jagtap and co-workers ${ }^{39}$ \\
\hline $\mathbf{1 8}$ & $0.043 \pm 0.017$ & This work \\
& $0.058 \pm 0.002$ & Jagtap and co-workers \\
& $0.021 \pm 0.003$ & This work \\
\hline $\mathbf{2 0}$ & & \\
\hline
\end{tabular}

a Rates were measured at $21{ }^{\circ} \mathrm{C}$ in sodium phosphate buffer $(0.1 \mathrm{M}, \mathrm{pH} 7.4)$ containing $1 \mathrm{mM}$ diethylenetriaminetetraacetic acid (DTPA).

To summarize, we have described preliminary results regarding a new synthetic pathway for obtaining 2,2,6,6-tetraethylpiperidin-4-one 1, a key intermediate in the synthesis of tetraethylsubstituted nitroxides. This procedure relies on the already established strategy through dienone $\mathbf{9}$, thereby allowing a late-stage introduction of the nitrogen atom in the structure and a more cost- 
effective preparation of ${ }^{15} \mathrm{~N}$-labelled nitroxide probes for enhanced EPR sensitivity. The overall unoptimized yield of piperidinone 1 is $3 \%$ over eight steps from ethyl acetoacetate $\mathbf{1 0}$. The principal advantages of the present protocol are the use of common and reliable reactions and the avoidance of expensive equipment for organic synthesis.

\section{Acknowledgments}

Work by N. Babić was supported by Sorbonne University Paris Cité (international PhD contract 2015) and the Ministry of Youth and Sports of the Republic of Serbia.

\section{Supplementary data}

Supplementary data (details of experimental procedures) associated with this article can be found in the online version at https://doi.org/10.1016/j.tetlet.2019.151207

\section{References and Notes}

1. Le Breton N, Martinho M, Mileo E, Etienne E, Gerbaud G, Guigliarelli B, Belle V. Front Mol Biosci. 2015; 2: 21.

2. Gigmes D, Ed. Nitroxide Mediated Polymerization: From Fundamentals to Applications in Materials Science, The Royal Society of Chemistry, 2015.

3. Bobbitt JM, Brückner C, Merbouh N. In Organic Reactions American Cancer Society, 2010; pp 103424.

4. Soule BP, Hyodo F, Matsumoto K-I, Simone NL, Cook JA, Krishna MC, Mitchell JB. Free Radic Biol Med. 2007; 42: 1632-1650.

5. Elas M, Ichikawa K, Halpern HJ. Radiat Res. 2012; 177: 514-523.

6. Swartz HM. Free Radic Res Commun. 1990; 9: 399-405.

7. Couet W, Brasch R, Sosnovsky G, Lukszo J, Prakash I, Gnewuch C, Tozer T. Tetrahedron. 1985; 41: 1165-1172.

8. Keana JF, Pou S, Rosen GM. Magn Reson Med. 1987; 5: 525-536.

9. Morris S, Sosnovsky G, Hui B, Huber C, Rao N, Swartz H. J Pharm Sci. 1991; 80: 149-152.

10. Ueda A, Nagase S, Yokoyama H, Tada M, Noda H, Ohya H, Kamada H, Hirayama A, Koyama A. Mol Cell Biochem. 2003; 244: 119-124.

11.Samuni Y, Gamson J, Samuni A, Yamada K, Russo A, Krishna MC, Mitchell JB. Antioxid Redox Signal. 2004; 6: 587-595.

12.Krishna MC, Grahame DA, Samuni A, Mitchell JB, Russo A. Proc Natl Acad Sci U S A. 1992; 89: 55375541.

13.Goldstein S, Samuni A, Hideg K, Merenyi G. J Phys Chem A. 2006; 110: 3679-3685.

14.Kinoshita Y, Yamada K-I, Yamasaki T, Sadasue H, Sakai K, Utsumi H. Free Radic Res. 2009; 43: 565571.

15.Paletta JT, Pink M, Foley B, Rajca S, Rajca A. Org Lett. 2012; 14: 5322-5325.

16. Yamasaki T, Mito F, Ito Y, Pandian S, Kinoshita Y, Nakano K, Murugesan R, Sakai K, Utsumi H, Yamada K. J Org Chem. 2011; 76: 435-440.

17. Hodgson JL, Namazian M, Bottle SE, Coote ML. J Phys Chem A. 2007; 111: 13595-13605.

18.Lampp L, Morgenstern U, Merzweiler K, Imming P, Seidel RW. J Mol Struct. 2019; 1182: 87-94.

19. Kinoshita Y, Yamada K, Yamasaki T, Mito F, Yamato M, Kosem N, Deguchi H, Shirahama C, Ito Y, Kitagawa K, Okukado N, Sakai K, Utsumi H. Free Radic Biol Med. 2010; 49: 1703-1709. 
20.Emoto M, Mito F, Yamasaki T, Yamada K-I, Sato-Akaba H, Hirata H, Fujii H. Free Radic Res. 2011; 45: 1325-1332.

21.Emoto MC, Yamada K-I, Yamato M, Fujii HG. Neurosci Lett. 2013; 546: 11-15.

22.Wang X, Emoto $M$, Sugimoto A, Miyake $Y$, Itto $K$, Amasaka $M$, Xu S, Hirata H, Fujii H, Arimoto $H$. Tetrahedron Lett. 2014; 55: 2146-2149.

23. Rajca A, Wang Y, Boska M, Paletta JT, Olankitwanit A, Swanson MA, Mitchell DG, Eaton SS, Eaton GR, Rajca S. J Am Chem Soc. 2012; 134: 15724-15727.

24.Wang Y, Paletta JT, Berg K, Reinhart E, Rajca S, Rajca A. Org Lett. 2014; 16: 5298-5300.

25.Sasaki K, Ito T, Fujii HG, Sato S. Chem Pharm Bull (Tokyo). 2016; 64: 1509-1513.

26. Karthikeyan G, Bonucci A, Casano G, Gerbaud G, Abel S, Thomé V, Kodjabachian L, Magalon A, Guigliarelli B, Belle V, Ouari O, Mileo E. Angew Chem Int Ed. 2018; 57: 1366-1370.

27.Sakai K, Yamada K, Yamasaki T, Kinoshita Y, Mito F, Utsumi H. Tetrahedron. 2010; 66: 2311-2315.

28. Wetter C, Gierlich J, Knoop CA, Müller C, Schulte T, Studer A. Chem - Eur J. 2004; 10: 1156-1166.

29.Schulte T, Siegenthaler KO, Luftmann H, Letzel M, Studer A. Macromolecules. 2005; 38: 6833-6840.

30.Sugawara Y, Yamada W, Yoshida S, Ikeno T, Yamada T. J Am Chem Soc. 2007; 129: 12902-12903.

31.Kuznetsov, NV, Guznenok, NK, Myrsina, RA. Ukr Khimicheskii Zhurnal. 1976; 42: 515-518.

32.Ghorai MK, Halder S, Samanta S. Aust J Chem. 2012; 65: 1262.

33.Kim J, De Castro KA, Lim M, Rhee H. Tetrahedron. 2010; 66: 3995-4001.

34.Sano H, Naruse M, Matsumoto K, Oi T, Utsumi H. Free Radic Biol Med. 2000; 28: 959-969.

35. Kao JPY, Rosen GM. Org Biomol Chem. 2004; 2: 99-102.

36.Sultani HN, Haeri HH, Hinderberger D, Westermann B. Org Biomol Chem. 2016; 14: 11336-11341.

37. Bézière $N$, Hardy $M$, Poulhès $F$, Karoui $H$, Tordo $P$, Ouari $O$, Frapart $Y-M$, Rockenbauer $A$, Boucher J-

L, Mansuy D, Peyrot F. Free Radic Biol Med. 2014; 67: 150-158.

38. Couet WR, Eriksson UG, Tozer TN, Tuck LD, Wesbey GE, Nitecki D, Brasch RC. Pharm Res. 1984; 1: 203-9.

39.Jagtap AP, Krstic I, Kunjir NC, Hänsel R, Prisner TF, Sigurdsson ST. Free Radic Res. 2015; 49: 78-85. 